\title{
El yacimiento de Tchaputchayna
}

Gustavo Le Paige, $s$. j.

La finalidad de la revista "Estudios Atacameños" es la de dar informes del trabajo en San Pedro de Atacama en forma ágil para que el público y los especialistas se mantengan al día en el desarrollo de los estudios sobre la cultura atacameña. Estos informes servirán para que cuando en el futuro se publiquen libros sobre el tema general o particular de esta cultura los lectores tengan ya antecedentes de los descubrimientos, hallazgos, excavaciones, etc., en forma aislada del contexto general de la misma cultura. El presente artículo es de este tipo, y trata un yacimiento en particular, denominado Tchaputchayna.

Esta forma de escribir es, lamentablemente, una manera un poco seca y aun nuestro deseo era escribir artículos que traten de temas específicos, como por ejemplo, una época determinada o un estudio sobre una tecnología o material en particular; vemos que esto es un ideal, pero en la práctica distorsiona el sentido profundo del desarrollo de una cultura especialmente en sus etapas de transición de una manifestación cultural a la otra. Tenemos la arqueología descriptiva que no presenta mayores problemas mientras que, por el contrario, la arqueología interpretativa es sumamente difícil. Esto se debe principalmente a que ningún yacimiento en San Pedro de Atacama es tan aislado y cerrado en sus manifestaciones culturales en un espacio y tiempo bien determinados que no tendría relaciones, contactos y semejanzas a los demás yacimientos arqueológicos. Unicamente en un trabajo de conjunto se podrá indicar el desarrollo cultural y social y ver lo que es común entre los diversos yacimientos y lo que es propio de cada uno. Este estudio de conjunto une todos los yacimientos en la evolución global de una secuencia de la misma cultura, a pesar de la incorporación de aportes afuerinos en la cultura.

Se necesitaría un tomo entero para describir en sus detalles el material arqueológico y sus correlaciones con otros yacimientos y otras culturas para cada yacimiento. Hay que señalar que en el mismo San Pedro de Atacama se descubrieron más de 50 yacimientos. Por lo tanto, lo que presenta- mos hoy día no es la totalidad en comparación con la realidad de una cultura.

En este trabajo tratamos algo de las manifestaciones culturales que se revelan en el yacimiento de Tchaputchayna. Escribimos acerca de los túmulos y del cementerio. Sobre este mismo yacimiento ya hemos escrito unas notas breves en 1957, en los Anales de la Universidad Católica de Valparaíso, Nos 4 y 5, en 1963 en los Anales de la Universidad del Norte $\mathrm{N}^{\circ} 2$, dedicado exclusivamente al Congreso Internacional de Arqueología de San Pedro de Atacama (6-13 de enero, 1963), en el cual en el mapa de la zona ubicamos el yacimiento Tchaputchayna $\mathrm{y}$, sucesivamente, en los Anales de la Universidad del Norte, $\mathrm{N}^{\circ} 3$, en el año 1964.

Desde este tiempo seguimos estudiando el yacimiento y aun, seguramente, no hemos agotado el estudio, por no decir que todavía estamos en sus comienzos. Tenemos una cantidad de datos y una visión general del yacimiento que es valiosa $\mathrm{y}$, por lo tanto, un aporte al estudio del desarrollo cultural atacameño.

\section{Ubicación del yacimiento}

El nombre Tchaputchayna es la antigua denominación de esta área que en el idioma "kunza" o "atacameño" significa "la bajada del zorro".

El yacimiento está ubicado en una parte actualmente desértica, entre los ayllos de Sequitor al norte, Coyo al oeste, Tulor al sur, y Beter al suroeste, a una distancia de $6 \mathrm{~km}$ y medio, aproximadamente, al sur del centro colonial de San Pedro de Atacama.

Siglos atrás, en este lugar crecían bosques de algarrobo y una variedad de arbustos cuya evidencia de sus troncos está en el terreno. Además de bosques tenía terrenos de cultivo que abarcaban una larga extensión, mayor al espacio donde hoy día se encuentran los túmulos. Estos últimos ocupan una superficie de $750 \mathrm{~m}$ por $350 \mathrm{~m}$ (ver Lámina 1). Al 
GUSTAVO LE PAIGE

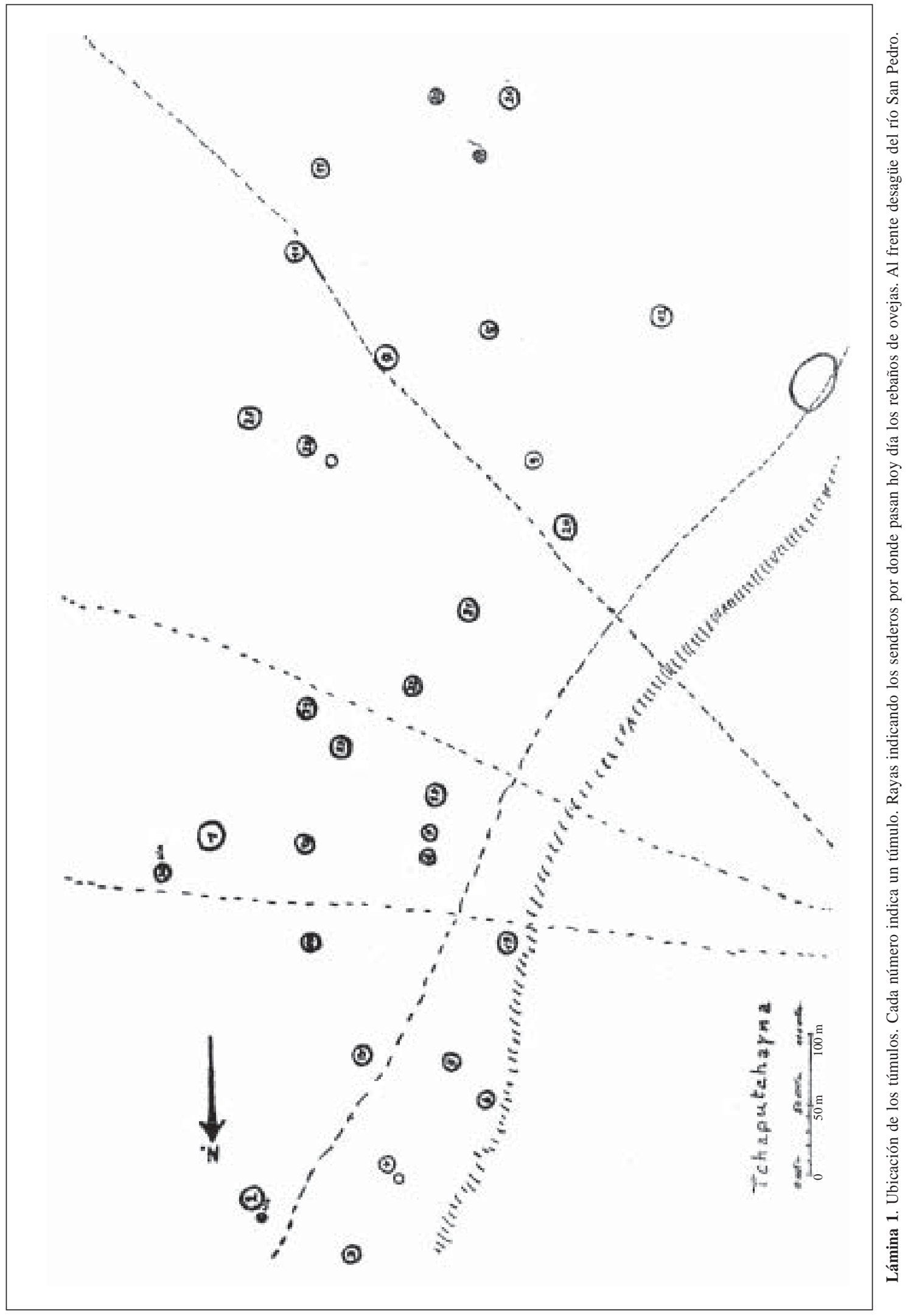


lado occidental del yacimiento pasa el desagüe del río San Pedro, que destruyó el cementerio ubicado en la parte sur de los túmulos y, afortunadamente, no alcanzó a destruir los túmulos mismos.

El yacimiento de Tchaputchayna tiene tres zonas de ocupación distintas en su funcionalidad una de otra.

1. Al sur, un cementerio que, en sus bordes, tiene pedazos de cerámica traída por el acarreo de las lluvias, en una pendiente suave de su topografía (Lámina 2).

2. Al centro, lo más importante de su extensión es la zona de túmulos con 30 sitios, en el cual hemos encontrado solamente dos entierros (Lámina 1).

3. Al norte, se encuentran únicamente campos de cultivo, los cuales, por el momento, no entran en nuestro estudio.

El terreno ha sido afectado por cambios climáticos en el pasado y en el presente. La parte occidental del cementerio fue destruida por el acarreo de las crecidas del río en épocas de lluvia y un poco por la acción de los vientos a causa de que el terreno es de arcilla muy dura (Lámina 2). La zona de túmulos fue erosionada por los vientos causando una baja del terreno en un metro por lo menos de su ocupación original.

\section{La industria lítica}

¿Los primeros habitantes de este yacimiento no han sido los de los túmulos y del cementerio? En todo el yacimiento se encuentran "bolas esferoidales" del tipo de Tchasquir (Industrias líticas de San Pedro de Atacama 1970: 64-67, Bolitas esferoidales en San Pedro de Atacama, Rehue 2: 65-74). Sin embargo, esto no comprueba que el lugar haya sido ocupado por la gente primitiva de Tchasquir. Estos artefactos están en Tchaputchayna por el acarreo del desagüe como lo hemos explicado en nuestro trabajo sobre Tchasquir. Tal vez estos artefactos han sido reutilizados. Los artefactos no solamente están desmoronados por golpes pequeños y repetidos, sino también desgastados por golpes fuertes para sacar lascas medianas en sus bordes.
Seguramente, el yacimiento ha sido ocupado antes de la llegada de la gente de los túmulos, pues el suelo está lleno de piedras talladas, de basalto negro y grano fino, cuya descripción se encuentra en nuestro informe: Anales de la Universidad del Norte 3: 23, 1964. "Para describirlo, lo mejor es compararlo con el Musteriense de Dordogne en Francia" y, en la misma página 73: "Material lítico que unos identifican como el Ayampitiense I de Argentina, II de Bolivia, de basalto negro, de grano finísimo". En el mismo parágrafo citamos "Los proyectiles del Tambiliense y del Mesolítico... que parece haber sido el centro de estas épocas en la vega de San Pedro de Atacama y en Solor-7". La repartición de este material lítico sobre la superficie no corresponde a los túmulos.

\section{El cementerio}

En el cementerio (Lámina 2) hemos excavado en 38 sitios que nos dieron 67 entierros que los distinguimos de tumbas, pues encontramos algunas tumbas comunes y tres sitios con varios cráneos, sin el cuerpo, que nos indicarían un entierro secundario. (En la zona de los túmulos encontramos sólo dos tumbas: una de guagua en urna, en el túmulo $20 \mathrm{y}$, la otra, de adulto, cerca del túmulo 23 , en la superficie de la tierra).

Antes de dar el contenido de cada tumba, deseo señalar dos características especiales de este cementerio:

1. Tres tumbas son únicamente de cráneos reunidos en el mismo lugar después de una ceremonia cuyos detalles desconocemos. Este hallazgo muestra la importancia, para los atacameños, del culto de la cabeza postmortem.

2. Varias tumbas presentan el difunto en cuclillas, no sentado, sino acostado de lado.

Frente al desorden que presentan algunas tumbas, debemos asegurar que no hemos notado en el cementerio otras excavaciones anteriores a las nuestras. Estas anomalías se muestran en la posición del cuerpo, la ubicación de partes del cuerpo, como ser una mandíbula separada a tantos centímetros del cráneo, etc., y, también se evidencian en el ajuar. Este desorden parece ser el efecto de erosiones causadas por las crecidas del río San Pedro, o de su desagüe, desembocando en el salar actual. Nosotros presenciamos las crecidas de este río en enero y febrero de 1961. A veces en las 


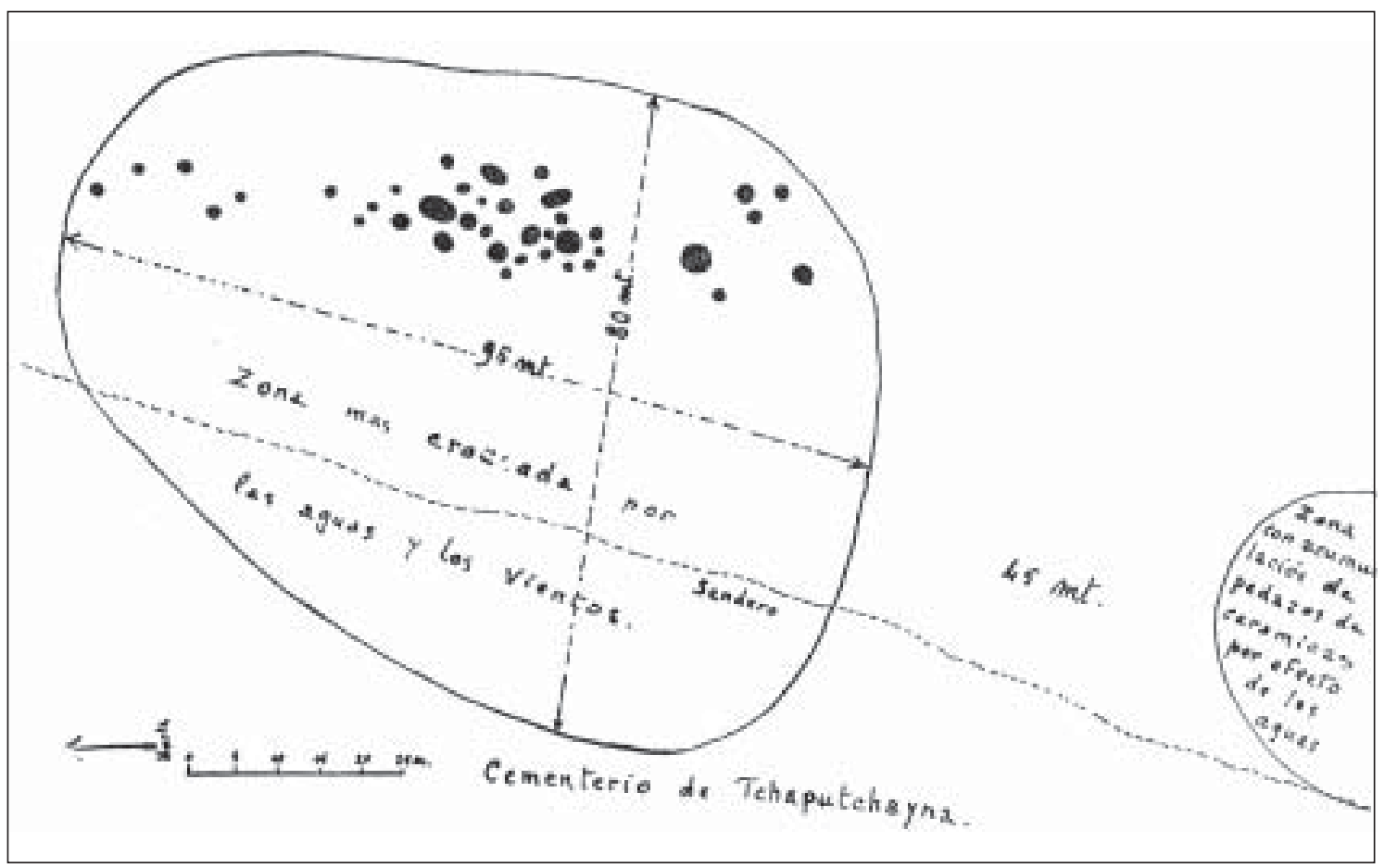

Lámina 2. Plano del cementerio indicando superficie original con 1) Tumbas excavadas y 2) Parte del cementerio destruido por las erosiones.

excavaciones se nota un óvalo blanco impreso en el suelo, que sería la evidencia de los restos de un cráneo erosionado de toda su calota, o dos arcos blancos en vez de las costillas, o cinco puntos blancos que serían los fémures, tibias y columna vertebral. Toda parte superior de los cuerpos ya no existe. Fue llevada en partículas infinitesimales por las aguas o por los vientos y se depositaron sobre el suelo cerca como colas de cometa.

En los cementerios que no han conservado su estructura original por las destrucciones debidas a la erosión, creemos que no sirve indicar la profundidad en la cual aparece el entierro, pues a veces, como lo hemos dicho, ya el cráneo y también en algunos casos las costillas, están a ras de la superficie, por causa de las erosiones.

Damos a continuación un resumen del contenido de cada tumba. Mantenemos la enumeración de las tumbas en orden de su descubrimiento, facilitando así los trabajos futuros para referirse a las notas de campo y a los ficheros definitivos del contenido de las tumbas y de la craneografía. Cuando escribimos "cráneo a $50 \mathrm{~cm}$ de profundidad", siempre entendemos la profundidad donde aparece el cráneo en su parte superior. No se trata de la base donde está asentado el entierro. En el siguiente catálogo damos la orientación del cuerpo en la tumba y otras características, mientras que el contenido del ajuar y la craneometría los resumimos en dos cuadros al final de este catálogo.

Tumba 3812. Un niño. Cuerpo totalmente destruido por la erosión, la cabeza dirigida hacia abajo.

Tumba 3813. Adulto, a $70 \mathrm{~cm}$ de profundidad, en cuclillas, pero acostado sobre el lado izquierdo, dirigido hacia el oriente.

Tumba 3814. Adulto al lado del 3813, en cuclillas, pero acostado sobre el lado izquierdo, dirigido hacia el occidente.

Tumba 3815. Adulto en cuclillas, sentado, mirando hacia el oriente, pero la cabeza dirigida hacia abajo. Sentado sobre un mortero o piedra para moler ya muy gastada.

Tumba 3816. Adulto en cuclillas, a unos $20 \mathrm{~cm}$ de profundidad en terreno muy erosionado. Dirigido hacia el occidente. 
Tumba 3817. Adulto a $50 \mathrm{~cm}$ de profundidad, en cuclillas acostado sobre el lado derecho dirigido hacia el NNE.

Las tumbas 3812 a 3817 están en un solo conjunto, con casi la imposibilidad de distinguir los diferentes pozos de sepultura por acción de las aguas que pasaron en largos períodos sobre el cementerio. Sigue otro grupo sin la posibilidad de distinguir los varios pozos:

Tumba 3818. Adulto a $40 \mathrm{~cm}$ de profundidad, en cuclillas, cráneo totalmente destruido al igual que el ajuar.

Tumba 3820. Adulto en cuclillas, dirigido hacia el este. Está ubicado bajo el número 3818.

Tumba 3821. Adulto a flor de tierra, ya destruido por la erosión, en cuclillas, dirigido hacia el oriente.

Tumbas 3822 a 3830 = 9 cráneos.

Se trata de un entierro, a unos $50 \mathrm{~cm}$ de profundidad, de nueve cráneos, sin mandíbula inferior, sin cuerpos, ubicados como lo dibujamos en la lámina 36 ya publicada en nuestro artículo "Cráneos Atacameños" en los Anales de la Universidad del Norte $\mathrm{N}^{\circ} 5$, 1966. Damos la posición de cada cráneo.

$\mathrm{N}^{\circ}$ 3822. Sobre el lado derecho mirando al norte.

$\mathrm{N}^{\circ}$ 3823. Sobre el lado derecho, pero a $45^{\circ}$ de inclinación para llegar a estar al revés mirando al SO.

$N^{\circ}$ 3824. Destruido.

$\mathrm{N}^{\circ}$ 3825. Derecho mirando al O (erecto).

$\mathrm{N}^{\circ} 3826$. Sobre el lado izquierdo mirando al ENE.

$\mathrm{N}^{\circ}$ 3827. Al revés mirando al E.

$\mathrm{N}^{\circ}$ 3828. Al revés mirando al SO.

$\mathrm{N}^{\circ}$ 3829. Al revés mirando al $\mathrm{O}$.

$\mathrm{N}^{\circ}$ 3830. Sobre lado derecho mirando al O.

En la misma tumba se encontraron dos pedazos del cráneo de un niño. El terreno es muy compac- to por la acción de las aguas; es seguramente un entierro antiguo sin haber sido molestado. Como ajuar, únicamente unos pedazos de alfarería negra pulida.

Acá tenemos, como en los tres casos enseguida, la prueba de un culto a la cabeza de post mortem. De ninguna manera se trata de un pozo donde habrían botado cabezas cortadas. En este caso la posición de los cráneos sería totalmente distinta, un amontonamiento de cráneos y las mandíbulas acompañarían los cráneos. En esta tumba no se encontró ninguna mandíbula. También no se puede tratar de un sitio donde las aguas de erosión habían congregado estos cráneos por las mismas razones ya expuestas.

A $40 \mathrm{~m}$ de distancia encontramos cinco cráneos (3832-3836) escondidos por bajo de un cachiyuyo. Probablemente uno de estos "aficionados" a los vasos de colección encontró otro entierro similar al precedente descrito, pues no hemos encontrado los cinco hoyos (tumbas) que habrían sido excavadas para sacar los cinco cráneos.

Tumba 3837. Adulto, cráneo ya destruido, pues se encontró a flor de tierra.

Tumba 3838. Uno de estos casos de Tchaputchayna. Varios huesos humanos de adultos, dos pedazos de cráneos, una mandíbula de guagua, un hueso de llama.

En la parte central del cementerio una urna sola (tipo campo de urnas de Tchaputchayna).

Enseguida describimos el entierro más extraño que hemos encontrado.

(3839 a 3849). El plano aquí junto, Lámina 3, nunca publicado, explica de qué se trata.

El 3839 a $30 \mathrm{~cm}$ de profundidad.

El 3840 bajo el 3839 y el 3841 a la misma altura.

El 3842 y el 3843 más abajo que el 3840 y 3841.

El 3844 a la misma altura que el 3843, pero con el 3845 (guagua) y el 3846 (niño) bajo los pies del 3843 extendido. 
Los 3847, 3848 y 3849 más abajo, ya a $1 \mathrm{~m}$ de profundidad.

El conjunto presenta cosas extrañas: dos cabezas sin cuerpo ni mandíbula; dos cuerpos están extendidos; el 3839 sobre lado derecho "mirando" al NO y el 3843 al SE sobre el lado izquierdo; el 3849 tenía la cabeza sobre su lado izquierdo, pero el cuerpo bajo él totalmente esparcido.

El 3839 no tiene ajuar; el 3840 que corresponde a la altura del 3841 , tenía un vaso medio negro y medio rojo, de la fase del negro "casi" pulido. Más abajo todos tienen alfarería negra pulida.

El 3848 tenía una tableta para rapé (pero destruida).

El 3843 no tenía el cartilaje de las articulaciones formado.

El 3842 (guagua) tenía un ipi (ver Mostny 1954) de hueso para tejer (Lámina 4.3).

El 3898 tenía la columna vertebral doblada pasada en la mandíbula y saliendo en la boca a causa de asentamiento del terreno (?).

Tumbas 3850-3851. El cuerpo 3850 está sentado dirigido hacia el oriente, pero las piernas casi extendidas. Tenía una espátula de hueso y un collar de cuentas chicas de turquesa bajo el mentón solamente. También una alfarería de transición entre la negra pulida y la negra "casi pulida", un pedazo de tiza blanca y una punta de flecha cerca de la espalda izquierda. Seguramente antes tenía su palo. Una urna chica al lado sur totalmente rota.

Entre 3850 y el 3851 una urna tamaño mediano, cuello largo, asas bajo el borde superior, tapada en primer lugar por pedazos de urna similar. En el cuello un cántaro negro pulido y, adentro de este, otro cántaro. En la panza tres cántaros negros pulidos, dentro de un plato hondo negro pulido perforado en su centro. Se encontraron también varias costillas de llama. Al lado occidental entre la alfarería negra pulida y la negra "casi” pulida.

Atrás del cuerpo 3851, a $50 \mathrm{~cm}$ de profundidad en posición en cuclillas, dirigido hacia el oriente, dos cántaros negros pulidos. El cuerpo es de un joven, dado a que el cartilaje de las articulaciones no está todavía formado. Al sur del 3851, muy

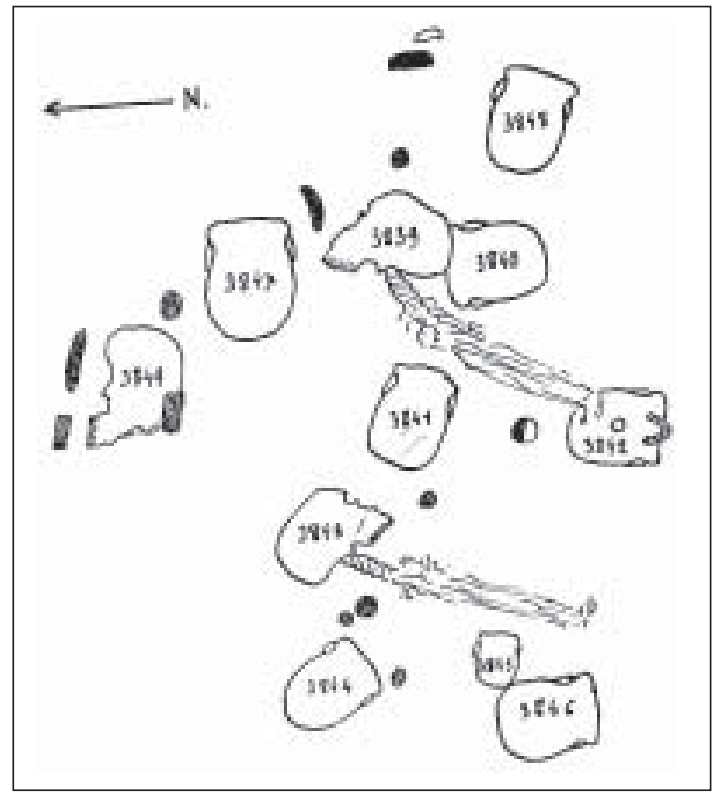

Lámina 3. Posición de los entierros de los cráneos 3839 a 3849 dentro de la misma tumba.

cerca del cuerpo, una urna mediana inclinada en un ángulo de $45^{\circ}$ hacia el sur, pero totalmente destruida. En el interior de ella había una sola costilla de llama.

Tumba 3952. Un cuerpo extendido en posición de norte hacia el sur, sin cabeza, pues ésta fue destruida por la erosión. El cuerpo mismo se encontró a flor de tierra. En su ajuar tenía pedazos de urna mediana, seis cántaros negros pulidos, entre los cuales, un antiguo botellón, con su cuello quebrado y al cual le ampliaron su abertura. Unas cuentas gruesas de turquesa.

Tumba 3853. A $70 \mathrm{~cm}$ de profundidad un cráneo dirigido hacia abajo, el cuerpo totalmente esparcido, sin mandíbula, mezclado con los huesos de una llama, completamente ubicada debajo del hombre, seguramente puesta allí el día del entierro.

Tumbas 3854 y 3855. Dos cuerpos juntos, a $1.40 \mathrm{~m}$ de profundidad; el 3854 mirando al sur y el 3855 mirando al este. El ajuar tenía la siguiente posición: una canasta de la cual sólo quedó su dibujo en la tierra, dentro de ella había un cántaro negro pulido y, dentro de éste, otro cántaro rojo pulido. El cuerpo 3854 tenía un collar de malaquita. Los pies de los muertos, al oriente, cuatro cántaros negros pulidos, uno con polvo fino de manganeso que necesita para hacer las alfarerías negras puli- 
das. Dos caracoles de agua dulce con tierra amarilla adentro, que se usa como colorantes.

Tumba 3856. Adulto, a $1 \mathrm{~m}$ de profundidad, mirando hacia abajo, en dirección sur.

Tumba 3857. Niño, a $1 \mathrm{~m}$ de profundidad, mirando hacia el sur.

Tumba 3858. Adulto, a $80 \mathrm{~cm}$ de profundidad, mirando al este: un cántaro negro pulido, cuentas chicas de malaquita.

Tumbas 3859-3860. Totalmente revueltos por las aguas, todo el ajuar mezclado con los huesos, una mandíbula, pedazo de cráneo de un niño (3860), fragmentos de cántaros negro pulido, fragmentos de cerámica negra incisa "juego de la cola" y dos trozos de cobre.

Tumba 3861. Adulto, al oriente del cementerio, a $20 \mathrm{~cm}$ de profundidad, mirando al este. Sin ajuar.

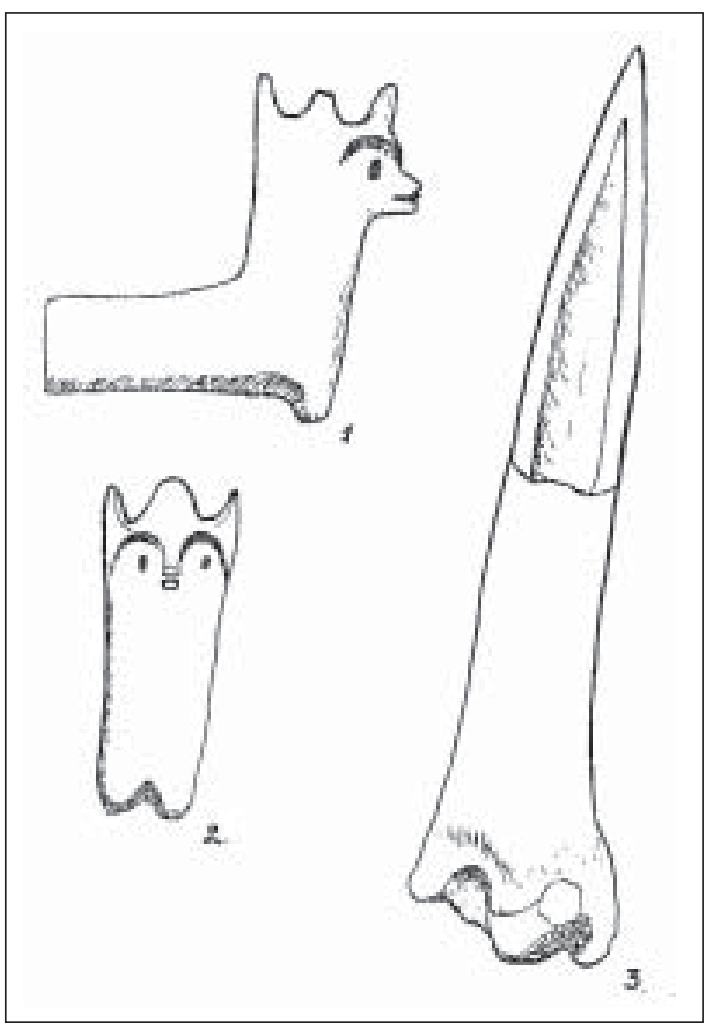

Lámina 4. 1) Pipa de greda negra con cabeza de llama (tumba 3821). 2) Frente de la misma pipa. 3) Ipi de hueso para tejer (tumba 3842). Ver Mostny (1954).
Tumba 3862. Igual a la anterior, más el entierro de una llama entera, con alfarería negra casi pulida, y un caracol de agua dulce (Lámina 10.5).

Tumbas 5057, 5058 y 5059. Un adulto con otros dos cráneos, sin cuerpos.

El 5057 fue destruido, a flor de tierra, sin ajuar.

El 5058, adulto, y 5059, un joven. De éstos se encontraron únicamente los cráneos ubicados al norte del 5057. Los tres mirando hacia el norte. Los dos cráneos acostados sobre el lado izquierdo. El 5058 no tenía mandíbula, mientras que el 5059 , con su mandíbula, estaba a una distancia de $15 \mathrm{~cm}$ del cráneo.

Tumba 5060. Adulto, a $40 \mathrm{~cm}$ de profundidad, mirando hacia el Quimal (poniente). Dos cántaros negros pulidos.

Tumba 5061. Adulto, a flor de tierra, mirando hacia el Láscar (SO), sin ajuar.

Tumbas 5063-5064. Dos adultos, uno a flor de tierra, el otro a $45 \mathrm{~cm}$ de profundidad. Cuatro cántaros negros pulidos, un caracol de agua dulce (Lámina 10.5).

Tumbas 5075-5076. Dos adultos en una sola fosa, pero con diferente ajuar. El 5075, adulto, dirigido hacia el sur. Cuatro cántaros negros pulidos.

El 5076, adulto, dirigido hacia el sureste. Dos cántaros negros pulidos. Los huesos largos de las piernas están pintados de rojo. Esto comprueba la existencia de un culto post mortem. Este hecho se verifica en otros cementerios.

Tumba 5100. Adulto en la parte norte del cementerio. Un cántaro negro, casi pulido, dos caracoles de agua dulce con pintura roja en polvo, dentro de ellos, confirma las tumbas 5075 y 5076.

En los dos cuadros siguientes, $N^{\text {os }} 1$ y 2 , damos primero el índice cefálico de los 33 cráneos, la deformación craneal y sus tipos, los cráneos destruidos, cuyos restos no permiten tomar su índice cefálico a otros datos, y el número de niños. En el segundo cuadro, la distribución del ajuar respectivo de cada entierro. 
Lo dicho anteriormente no muestra la totalidad del cementerio. Arriba se describió sólo lo que ha sido recuperado en las excavaciones efectuadas. A causa de las condiciones climáticas del yacimiento, muchas otras tumbas han sido erosionadas dejando sobre el terreno cantidades de fragmentos de cerámica. A través de una recolección de esta cerámica podemos comprobar que el cementerio es anterior a la alfarería negra pulida, pues se encontraron restos de cerámica hechos con greda primitiva de color gris con muchos granos blancos, gris con engobe oscuro, gris con engobe carmín oscuro, urnas de color tierra oscura o gris, con asas gruesas verticales a horizontales (Lámina 5). Esta cerámica que aquí llamamos primitiva es de suma importancia, porque nos revela otra etapa en el desarrollo de la cultura atacameña. Esta cerámica se encuentra en otros yacimientos de San Pedro de Atacama, y hasta ahora no ha sido sometida a un análisis riguroso. Este trabajo esperamos efectuarlo en un próximo futuro.

Además de la cerámica primitiva, se encuentra en la zona de túmulos del mismo yacimiento un tipo de cerámica que vamos a describir. Tanto en los túmulos como en la superficie del cementerio se encuentran fragmentos de las urnas medianas y chicas, todas las variedades de la alfarería negra pulida, negras, gris o café y el rojo pulido, incisas con el "juego de la cola" y una cantidad de fragmentos de cerámica provenientes de los países vecinos, Bolivia y noroeste argentino, cuya clasificación precisa se comenzó a hacer y esperamos dar el primer informe en el número 3 de Estudios Atacameños.

Las conclusiones a interpretaciones sobre este cementerio los hemos dejado para un trabajo final, por cuanto consideramos importante en la interpretación de un lugar arqueológico, tomar en consideración los otros cementerios. Los hechos secos indicarían que este cementerio comprueba una interpretación ya dicha en otros trabajos nuestros: que el atacameño practicaba un culto Post mortem.

\section{Los túmulos}

La segunda zona, que especificamos en la introducción, se constituye de túmulos formados por una urna grande y miles de fragmentos de huesos, cerámica y otros artefactos. Acá tratamos de

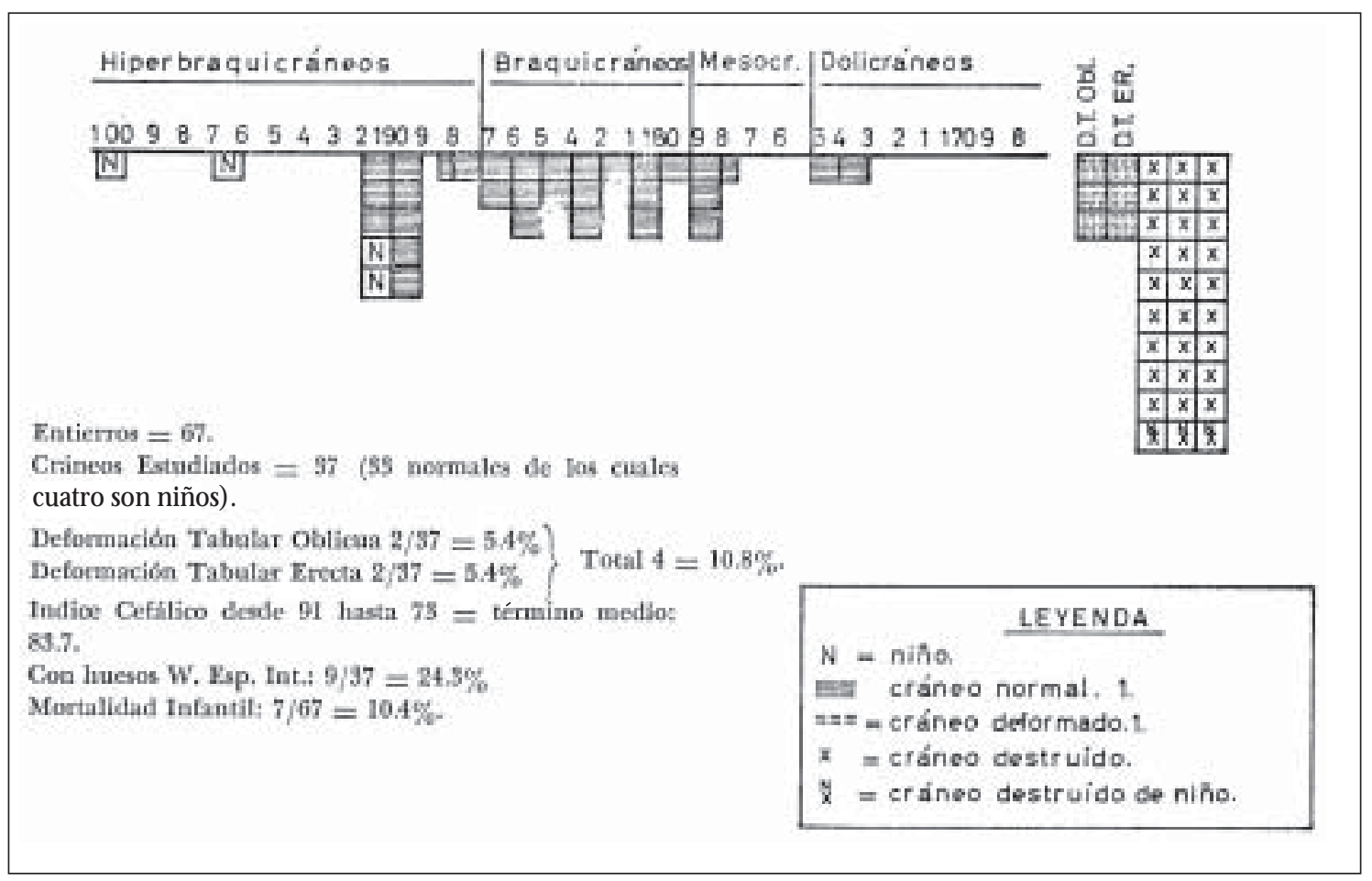

Cuadro 1. Craneometría del cementerio de Tchaputchayna. 
EL YACIMIENTO DE TCHAPUTCHAYNA

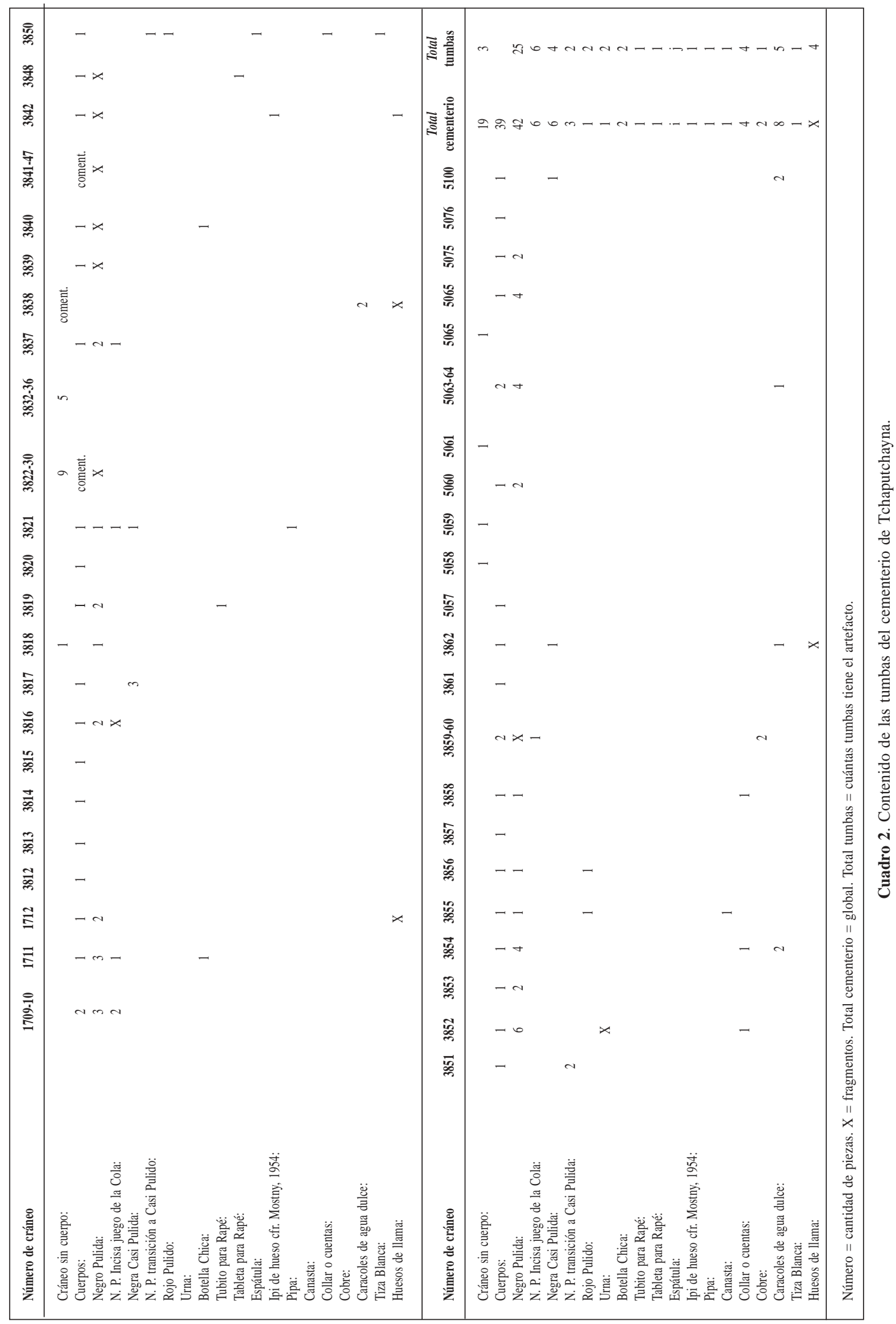


dar la tipología de las urnas (Lámina 5) y una descripción sumaria de la cerámica recolectada y otros artefactos que recogimos de la superficie. En el plano, Lámina 1, indicamos la posición de cada túmulo con su número respectivo. Cada número indica un túmulo y en la siguiente tabulación damos el número de urnas que contenía el túmulo, las vasijas grandes y medianas que fueron enterradas en el suelo y que forman lo que ahora llamamos un túmulo en el cual quedan destruidas, quebradas o salvadas. El área de cada túmulo lo consideramos no simplemente el lugar ocupado por las urnas sino también el espacio que ocupan los fragmentos de estas urnas y alfarería destruidas y esparcidas por la erosión (vientos, lluvias y el paso de las tropas de ganado) en la superficie. A veces este material es tan abundante que une un túmulo con el otro, como el 7 al 10 y el 14 al 15. El número de los túmulos no indica nada acerca de su prioridad o importancia; únicamente sirve para ordenar nuestro trabajo.

Las urnas grandes y medianas tienen varios tipos de formas: cónicas, casi esféricas, aplastadas, de cuello largo, etc. (Lámina 5), también las medidas varían desde $1.20 \mathrm{~m}$ de altura hasta $50 \mathrm{~cm}$, posiciones distintas de esas planas o redondas, verticales u horizontales, grandes en la parte más ancha, o chicas cuando se ubican bajo los bordes superiores de las urnas. Se nota tam-

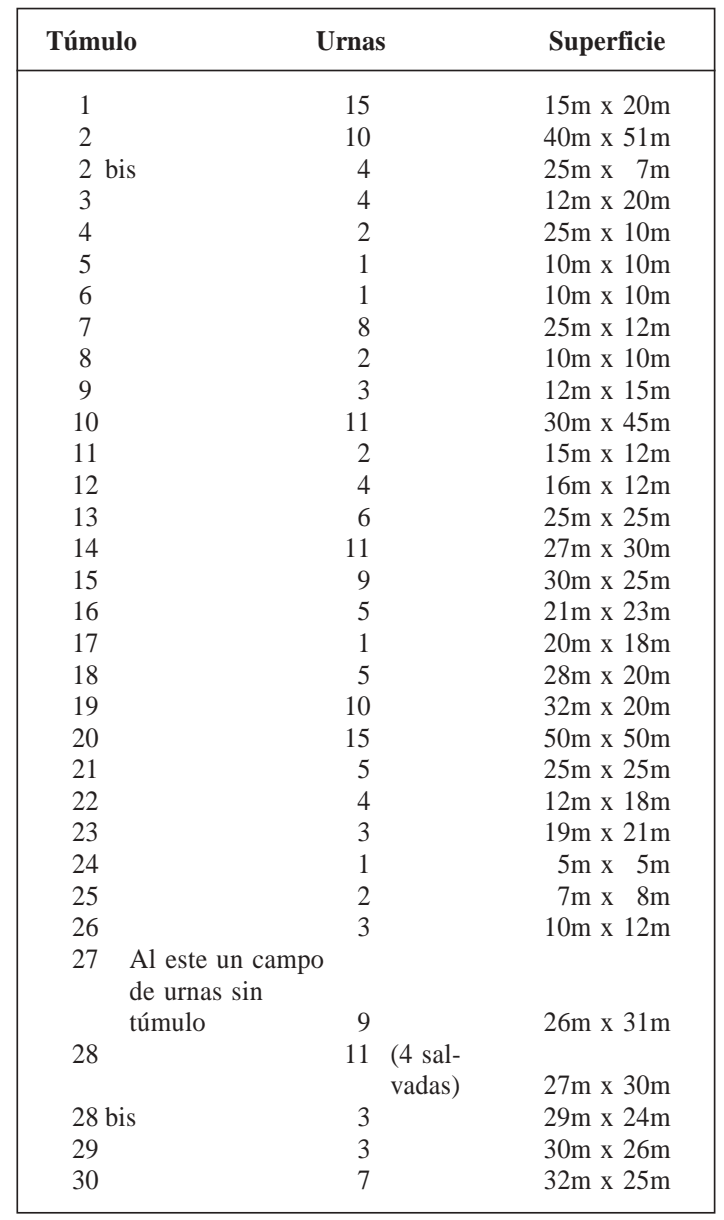

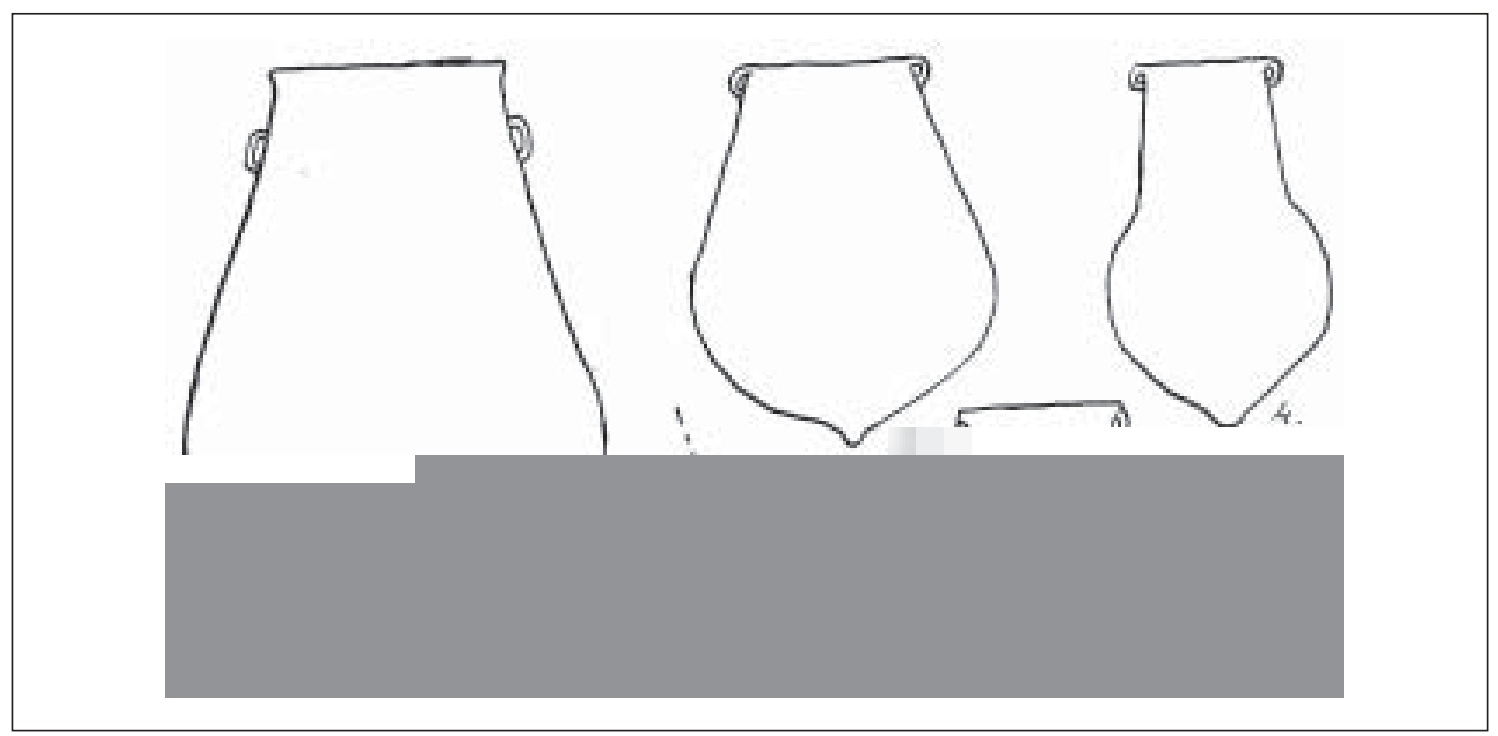

Lámina 5. Tipos de urnas, escala 1 a $10 \mathrm{~cm}$. 1) Borde encorvado, forma cónica, asa plana horizontal. 2) Borde simple, forma periforme, asa plana horizontal. 3) Borde simple, forma cónica, asa bajo el borde. 4) Cuello largo, asa bajo borde superior, borde recto. 5) Borde doblado en ángulo, forma esférica, asa bajo el borde superior. 
bién que estas urnas presentan tres tipos de cocción de la greda: una sola capa; dos capas, una color tierra al exterior y la otra negra al interior; tres capas, una negra entre dos color tierra. Los bordes superiores también presentan viariantes: rectos, inclinados, encurvados, doblados en ángulo.

Desde todos los túmulos hemos recogido vasos de alfarería negra pulida, enteros o en fragmentos, los cuales tienen todas las formas de la cerámica conocida, como igual en el cementerio. Estos fragmentos pueden dividirse en: 1) cerámica grabada con el "juego de la cola", contemporánea al negro pulido (láminas $6,7,8,9$ ); 2) muy pocos fragmentos de cerámica "casi" pulida primitiva, 3) poca cerámica, algunas con bordes; 4) cerámica Aguada (Argentina); 5) otros fragmentos cuyo origen es discutible.

Ahora damos una lista de características especiales de cada túmulo. Conviene señalar que todos los túmulos tienen cerámica negra pulida en todas sus fases y variantes.

Túmulo 1. Salvada la urna más grande de $1.20 \mathrm{~m}$.

Túmulo 2. Varias urnas chicas destruidas.

Túmulo 3. Urnas medianas, pintadas rojo y gris en el interior.

Túmulo 4. Urna mediana gris, interior negro, otra beige gris. Cántaro rojo pulido, 1 vaso rojo grabado con "juego de la cola", otro negro pulido pero de pasta rojiza.

Túmulo 5. Dos urnas grandes rojizas, capa negra afuera. Urnas medianas rojizas con manchas negras de cocción, urnas medianas rojizas con bastantes granos.

Túmulo 6. Urna chica negra al exterior, gris en el interior. Muchas escorias de fundiciones (Lámina 11).

Túmulo 7. Urnas grandes con bastante grano, cántaro rojo pulido de fondo plano (un pedazo) que tendría $23 \mathrm{~cm}$ de diámetro y otro más grande (un pedazo), cántaros gris y rosado con bastante grano, una cantidad de fragmentos de alfarería negra pulida con "el juego de la cola".
Túmulo 8. Urna de cuello muy largo. Una alfarería rojiza imitando la negra pulida. Una pipa de greda.

Túmulo 9. Un vasito chico con tierra negra adentro. Varios trozos de cerámica negra pulida con el "juego de la cola". Muchas piedras talladas de obsidiana, chert y variedades gris.

Túmulo 10. Pedazos juego de la cola, tres pedazos de cerámica rosada con granos blancos, tres pedazos de pipa de greda, un fragmento pintado rojo con línea negra y fondo blanco.

Túmulo 14. Un bloque de obsidiana en forma de chopper (!).

Túmulo 18. Un pedazo de cerámica rojo oscuro pulido contemporáneo al negro pulido.

Túmulo 19. Un asa de cerámica primitiva gris con engobe y granitos blancos.

Túmulo 20. Unico caso de entierro de guagua en urna (ver cráneo número 5066).

Túmulo 21. Seis pedazos de pipas, una rojiza con granos blancos, un pedazo de plato rojo. Pedazos de cerámica con juego de la cola, un hacha de piedra. Raspador doble y cuchillo de cuarcita.

Túmulo 23. Al lado de una sepultura de adulto (cráneo 5067), tapada por una gran laja triangular de basalto negro de grano fino. Un borde de alfarería primitiva. Un pedazo de pipa.

Túmulo 24. Un pedazo de alfarería negra pulida con engobe, el interior de tierra ordinaria.

Túmulo 25. Un urna mediana con fondo o base en forma de disco.

Túmulo 26. Cinco pedazos de cerámica rosada con granitos blancos con borde interior superior pintado de rojo. Pedazos de cerámica con juego de la cola.

Túmulo 27. Cuatro urnas salvadas: una grande y tres medianas. Cerámica ungulada. Cerámica con juego de la cola, de los cuales un pedazo grande con un dibujo muy escaso. Pedazos de cerámica Aguada. 


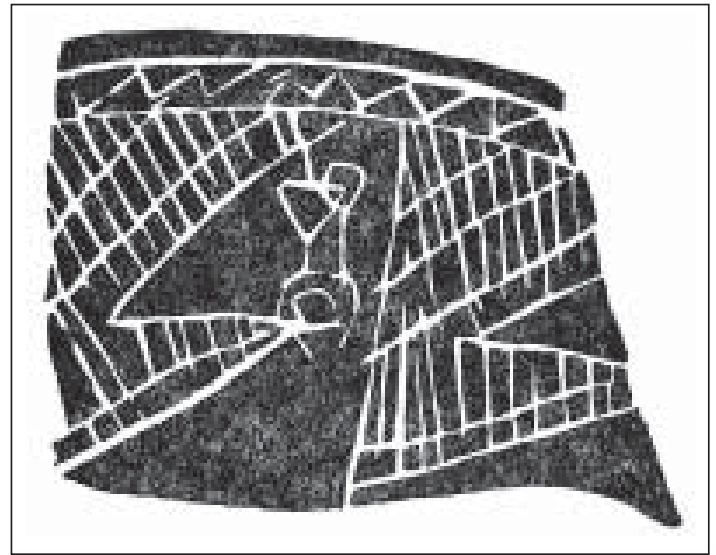

Lámina 6. Cerámica negra pulida incisa con el "juego de la cola" (una de las formas cuantitativamente no común) túmulo 27. Tamaño reducido a la mitad.

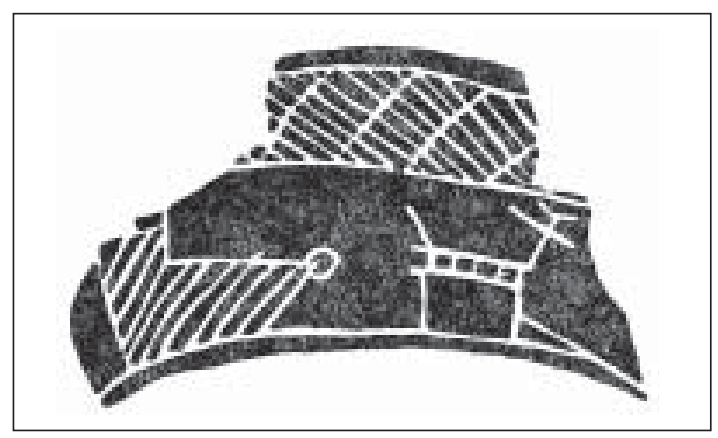

Lámina 8. Cerámica negra pulida incisa con una llama grande típico en estas incisiones y una chica. Desde todos los cementerios de San Pedro se encontraron sólo tres especímenes de este grabado.

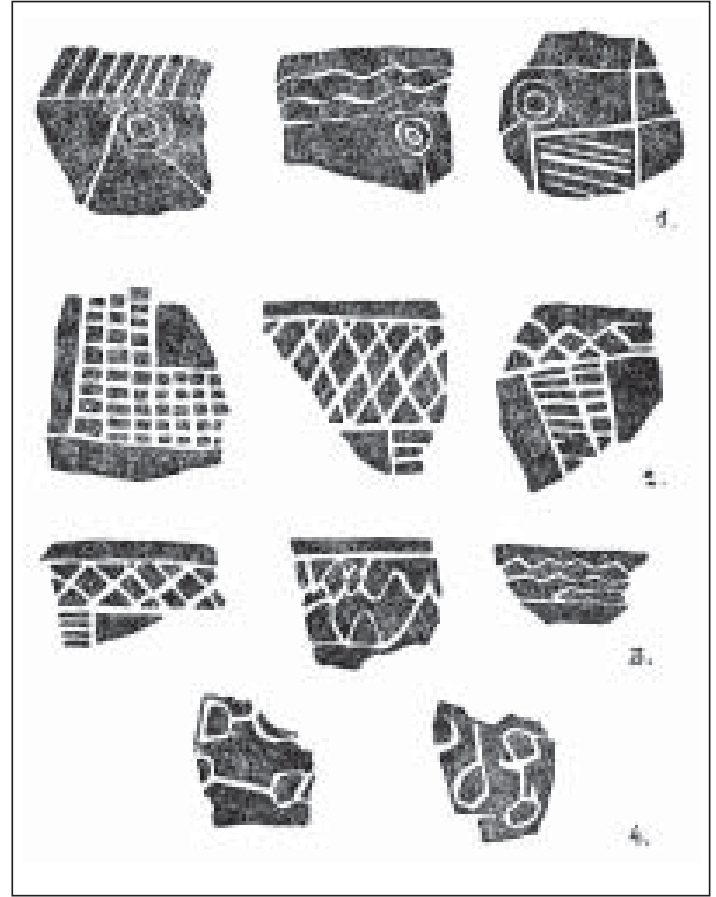

Lámina 7. Estilos del "juego de la cola". 1) Fragmentos indicando solamente las colas. 2) Fragmentos indicando el cuello de la llama. 3) Bordes que complementan el campo de incisión del uno y dos, colas y cuerpos, de llamas. Los vasos enteros de estos fragmentos han sido publicados en Le Paige: 1963 lámina VII Figs. 9 y 10, lámina V: Figs. 5 y 6. 4) Abstracción del "juego de la cola" mostrando talvez una evolución en los estilos anteriores, 1, 2, 3. Los vasos enteros indicando este estilo han sido publicado en Le Paige 1964: Lámina 133 figuras 1 y 2.

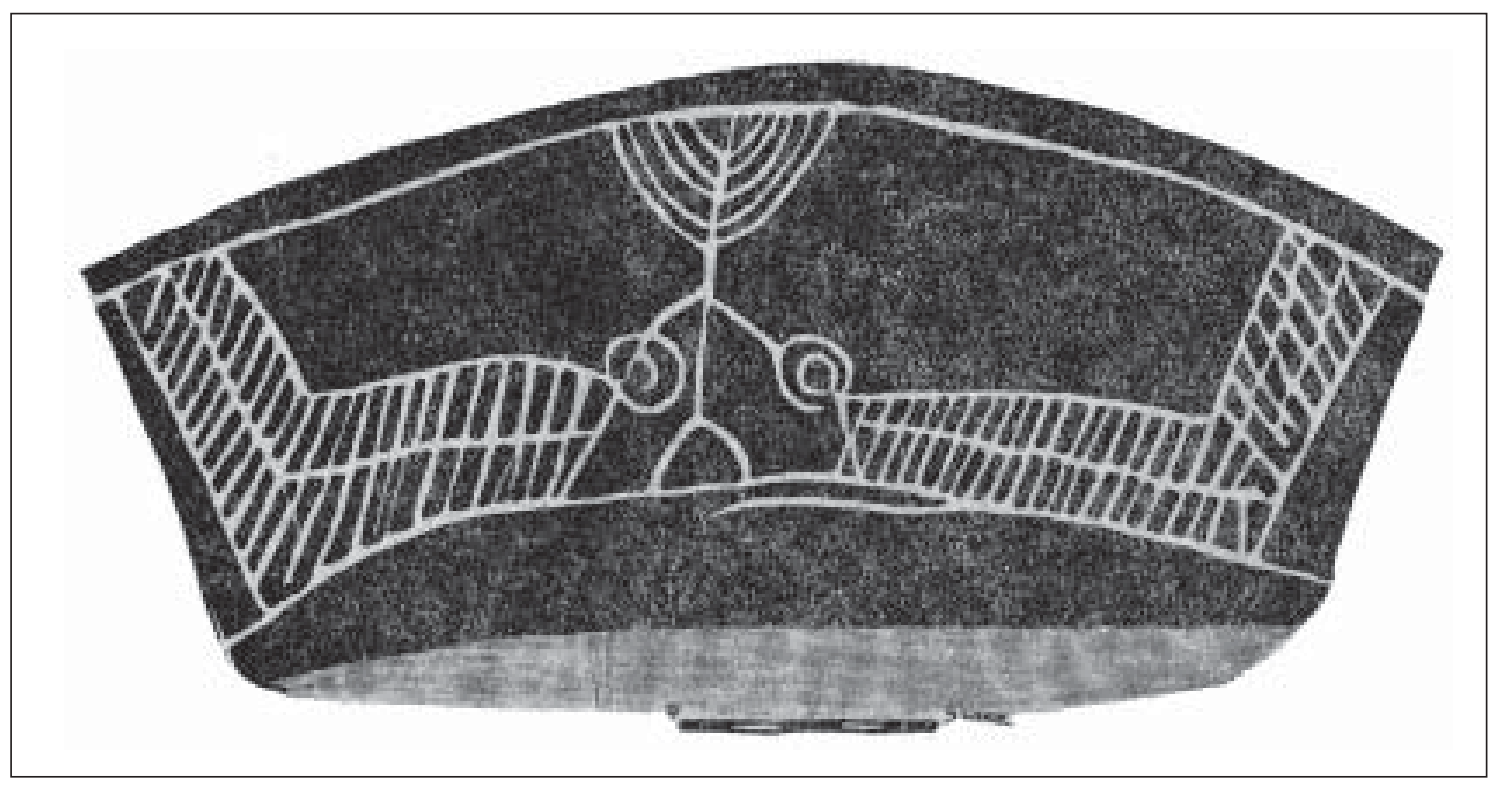

Lámina 9. Cerámica negra pulida, incisa con el tercer variante dentro del estilo "juego de la cola". 
Túmulo 28. Un fragmento de pipa.

Túmulo 29. Cántaro gris obscuro con engobe. Cántaro rosado con granitos blancos. Cerámica rojo carmín y otra "café con leche". Dos pedazos de pipa. Pedazos de cerámica con juego de la cola.

Insistimos que toda la superficie indicada está llena con pedazos de cerámica esparcidos por las erosiones. Estos fragmentos de cerámica se encuentran a lo largo de todo el yacimiento. Además de las variedades ya señaladas, alfarería negro pulida y grabada con el juego de la cola, se encuentran otras variedades y tipos: Cerámica corriente, Aguada pintada, Ciénaga pintada, Candelaria pintada, Condorhuasi pintada y grabada, las Mercedes grabada y varios otros fragmentos que aún no se reconoce su procedencia; bordes de cántaros grabados y listones grabados; fragmentos de cántaros antropomórficos: caras, pie humano, arco ciliar; zoomórficos: cabeza de llama, caricatura de animales. En cuanto a los fragmentos pintados nos parece que su origen es el NO argentino, aunque revelan una variedad hasta ahora no conocida en este lugar.

El siguiente es el número de fragmentos recogidos y tentativamente clasificados: hemos descrito en los Anales de la Universidad del Norte $\mathrm{N}^{\circ} 3$ (1964). El Precerámico en la Cordillera Atacameña y los cementerios agroalfareros de San Pedro de Atacama: 23 y láminas 31, 32, 33. Estos artefactos los hemos comparado al Musteriense, al final del Paleolítico, por otros artefactos y sobre todo al Mesolítico que se caracteriza por la aparición del pedúnculo en las puntas de flechas. Para la época del Neolítico, que es el período de los túmulos, tenemos 5650 puntas de flechas en obsidiana, chert, vidrio natural, etc. En este yacimiento hemos encontrado núcleos de obsidiana y artefactos del mismo material: raspadores, cuchillos, leznas como igualmente de otra materia prima más que la obsidiana; en cuarzo, numerosos perforadores, en piedra, palas, azadones, hachas, mazas o martillos para quebrar el caliche de cobre y raspadores de unos $15 \mathrm{~cm}$. Se encontró también un mortero chico de forma oblonga, hecho en piedra que semeja a un pez y que podía haber servido para moler el rapé. Otros objetos de piedras han sido encontrados, como 31 tembetás (Lámina 10.2), de los cuales cuatro planos y un silbato de piedra.

\section{Otros artefactos}

En metal recogimos topos de plata, cinceles, anillos y otros adornos, hachas de cobre como

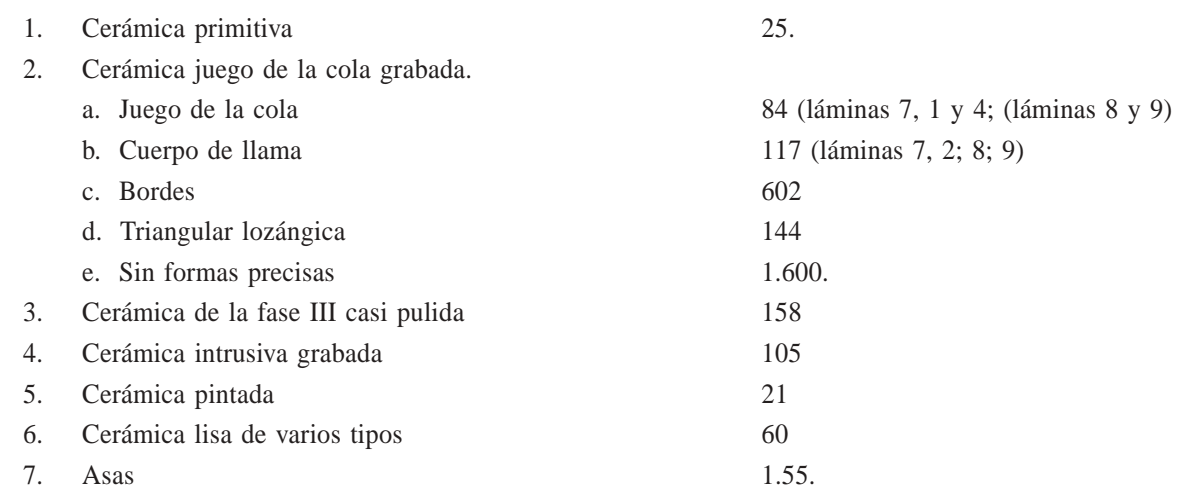

25.

84 (láminas 7, 1 y 4; (láminas 8 y 9)

117 (láminas 7, 2; 8; 9)

602

144

1.600 .

158

105

21

60

1.55 .

No hemos contado la cerámica negra pulida y los fragmentos de urnas de pasta corriente que sumarán miles.

\section{Material lítico}

En este mismo campo de túmulos hemos recogido material lítico de la época del Paleolítico que ya también una linda maciza de bronce (Lámina 11.3).

Las conchas marinas y caracoles de agua dulce sirvieron para fabricar muchos tipos de adornos para collares y breloques (Lámina 10.3, 4, 5). Lamentablemente los objetos de madera, como las tabletas de rapé, no se conservaron a causa de la 


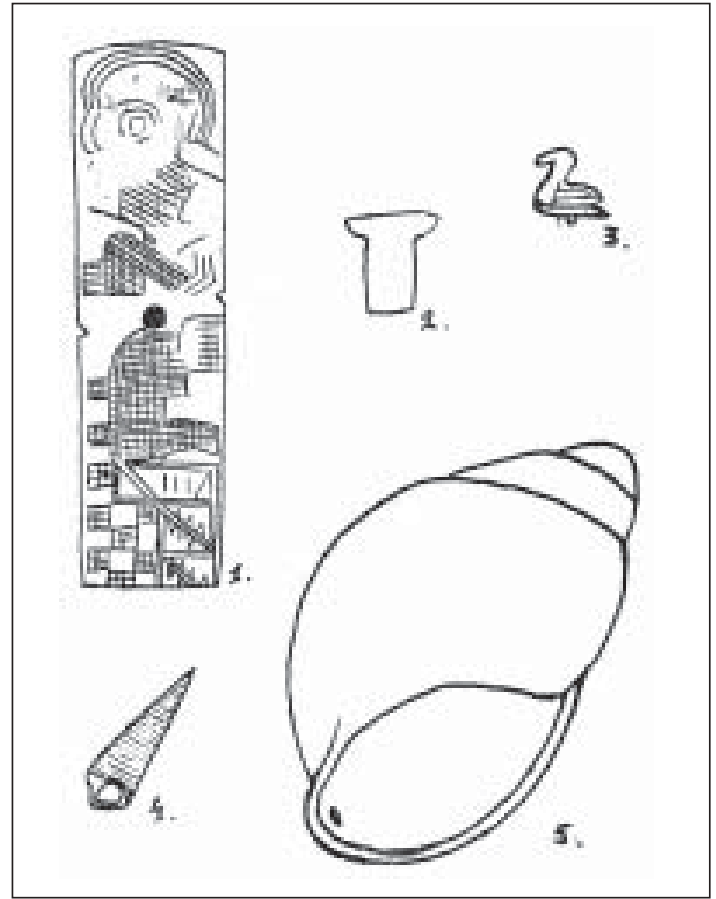

Lámina 10. Conjunto de artefactos del yacimiento. 1) Tortera de hueso (?) grabada con la parte superior, muy borrosa. 2) Tembetá. 3) Adorno de un collar; figura de pato hecha sobre jaspe (?). 4) Caracol chico con un hoyo, uno de los tantos adornos. 5) Caracol grande de agua dulce (tumbas 3862, 5063-5064, 5100 ), en tumbas se encuentran con colorantes y en túmulos sirven como materia prima para fabricar cuentas para los co1lares.

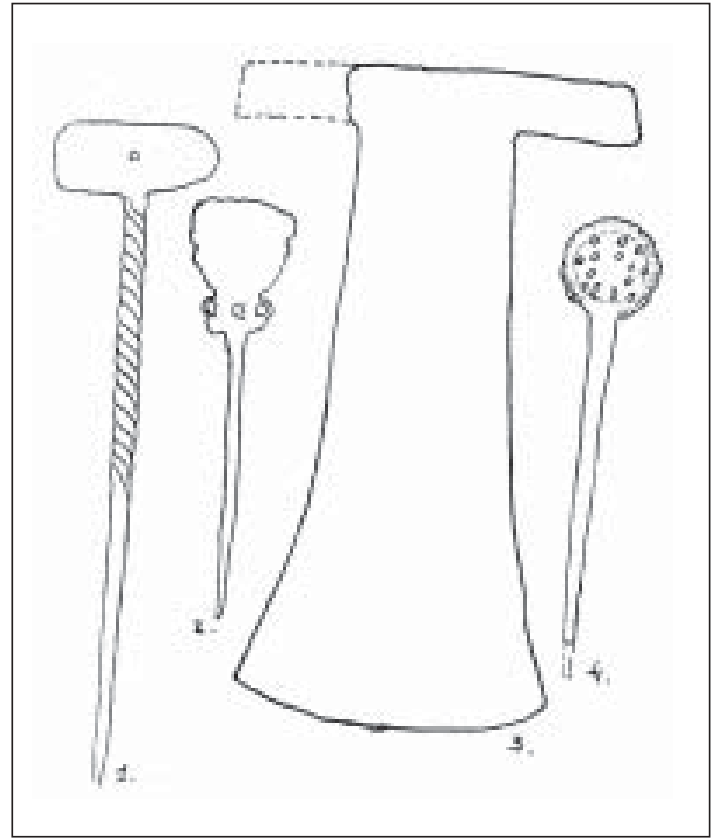

Lámina 11. Artefactos en metal. 1) Topo de bronce (?). 2) Topo de planta. 3) Maciza de bronce (hacha). 4) Topo de metal (?).

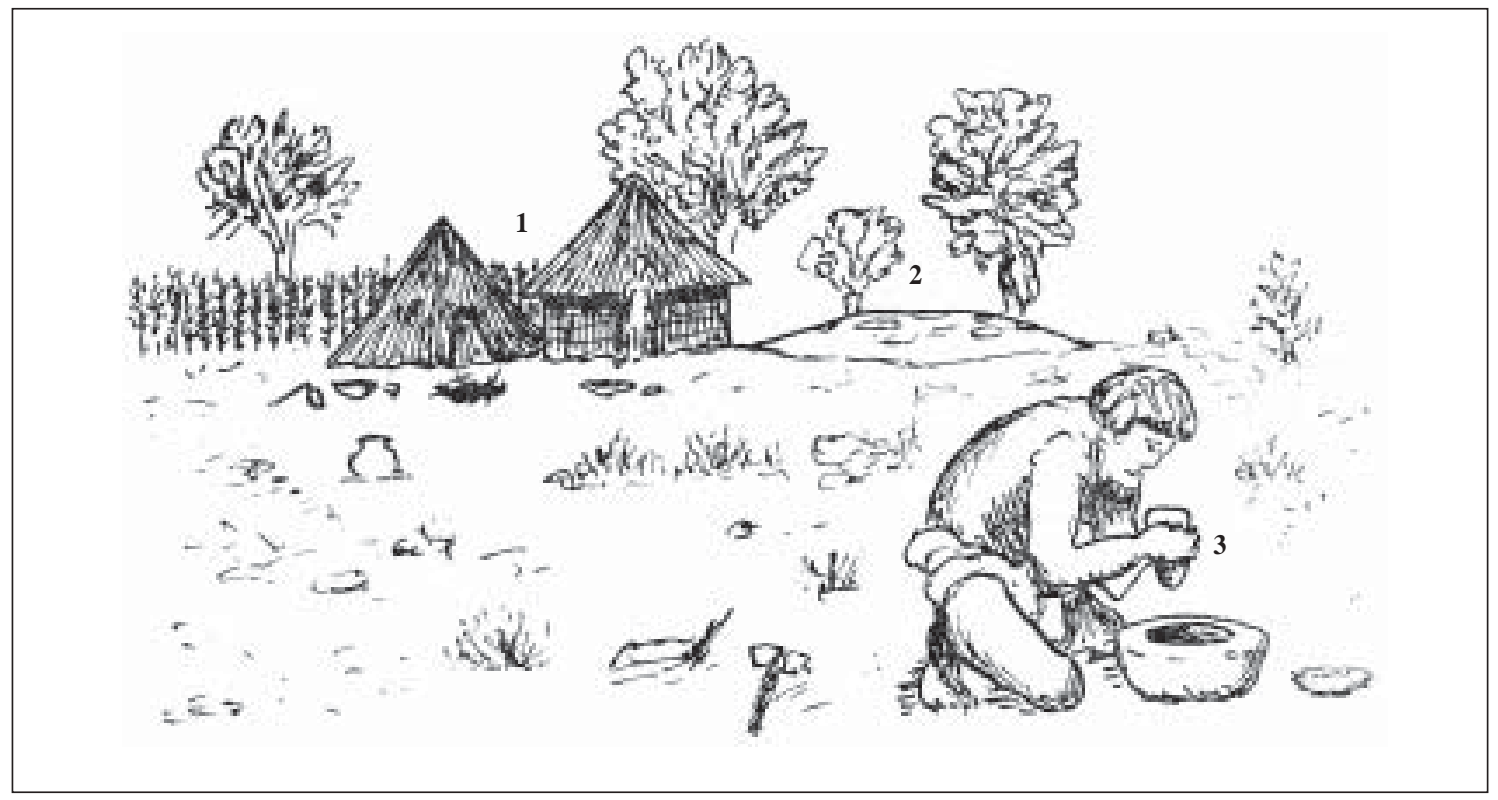

Lámina 12. Reconstrucción hipotética del medio ambiente de Tchaputchayna. Contrasta con la Lámina 1 mostrando el aspecto actual del lugar. 1) Arboles con chozas y plantaciones de maíz (fondo). 2) Túmulo con las urnas y sitio ritual (lado derecho). 3) Morteros y azadones, martillos. Lugar de trabajo de herramientas (taller). 
composición del terreno y su ubicación topográfica cerca de un desagüe del río San Pedro. Una linda tortera (Lámina 10.4), de hueso grabado, comprueba que los escultores no faltaban en esta época.

\section{Conclusiones}

No hemos encontrado ningún tipo de estructura pese a que existen estructuras de tapia en Tulor y Coyo a pocos kilómetros de Tchaputchayna y a pesar de que el conjunto de cerámica y otros artefactos en estos dos últimos yacimientos es semejante a aquello de Tchaputchayna. No entramos en más detalles sobre estos dos yacimientos porque ya estamos preparando su descripción y catálogo de objetos encontrados en ellos para el número tres de Estudios Atacameños.

A primera vista, el cementerio parece más antiguo que los túmulos, a causa de que las urnas de los túmulos tienen una apariencia reciente. Sin embargo, todo el contexto de los túmulos descrito arriba, indicaría que los túmulos son de la misma época que el cementerio, en cuanto que la cerámica en los túmulos y el cementerio, en su conjunto, es la misma. ¿Qué función, entonces, tenían los túmulos en este yacimiento? Es el hábitat, un lugar de viviendas o chozas (Lámina 12) de ramitas en medio de bosques poco densos o casas construidas bajo árboles que permitían al mismo tiempo el cultivo. Su estructura era semejante al ayllo de hoy día en San Pedro de Atacama. Alrededor de cada habitación servía como un sitio ritual, donde se enterraban las urnas de todo tamaño, cada una acompañada con huesos de llama u otros auquénidos. Creemos, seguramente, que la zona de túmulos es un poblado con viviendas, puesto que, en cada túmulo, o a su lado, hay morteros con sus manos de piedra para moler, hachas y azadones de piedra, martillos para quebrar caliche. Por todas partes se halla este material, además de que las cerámicas se encuentran en fuerte densidad en los túmulos.
Hemos también buscado, a ver si pudiera encontrarse un túmulo de mayor importancia que el resto, alrededor del cual se habrían colocado los otros, pero no obtuvimos ningún resultado positivo. También hemos tratado de encontrar un túmulo principal a través de un estudio de ubicación topográfica o con orientación astronómica, estudiando los ángulos entre un túmulo y otro, en relación con el este, el norte o el oeste. Este estudio no ha revelado nada en especial. Este hecho, negativo en un sentido, es positivo por otro, ya que nos confirma la idea que expresáramos en otros trabajos, que los atacameños en toda su historia, presentan una ausencia de clases sociales o de puestos de jefes hereditarios. El cementerio nos indicaría lo mismo. No hay tumba más importante o que nos revele ritos especiales acerca de una persona como autoridad. Aun en el cementerio no hemos encontrado uniformidad en los entierros; el caso de las tres tumbas con tres cráneos sin cuerpos es una prueba del culto de la cabeza post mortem, pero no indicaría que esto se realiza en favor de un privilegiado.

En este trabajo nos hemos esforzado en dar el contenido de este yacimiento, sin entrar en todo el problema de interpretación sociocultural de la cultura atacameña, porque creemos que esto resultaría más auténtico y verdadero cuando se hace en contraste con el contenido de varios otros yacimientos en la localidad de San Pedro de Atacama. Como lo hemos ya dicho, estamos preparando el estudio de otros tres yacimientos de poblados y cementerios en Coyo, Tulor y Solor- 4 . Vamos a seguir la misma metodología, primero, dar el contenido de estos lugares y después entraremos en la interpretación. Sin dejar de lado que, al mismo tiempo, estamos preparando una tipología más minuciosa de la alfarería de San Pedro de Atacama y de otros artefactos. Insistimos que un estudio verdadero no termina una vez escrito. Mucho más tiene validez este planteamiento tratándose de una zona con 50 yacimientos. 